\title{
Spawanie grubych blach miedzianych metodą MIG-SpeedPuls bez podgrzewania wstępnego
}

\author{
MIG-SpeedPuls welding thick plates \\ of copper without preheating
}

\section{Streszczenie}

W artykule przedstawiono wyniki badań doświadczalnych, dotyczących spawania miedzi bez podgrzewania wstępnego złączy doczołowych metodą MIG w odmianie SpeedPuls w pozycji PA. Omówiono spawalność miedzi, możliwość jej spawania bez podgrzewania wstępnego oraz wydajność spawania, geometrię i budowę makrostrukturalną uzyskanych spoin.

Słowa kluczowe: spawanie, miedź, MIG

\begin{abstract}
This paper presents the results of experimental studies devoted to copper MIG (SpeedPuls) welding in PA position without preheating. The article discussed the weldability of copper, possibility and performance of copper GMA welding without preheating. The geometry and macro-structure of obtained welds has been described.
\end{abstract}

Key words: welding, copper, GMAW

\section{Wstęp}

Charakterystyczne właściwości miedzi i jej stopów, np. wysokie przewodnictwo elektryczne i cieplne (do 10 razy większe niż stali), odporność na wiele agresywnych substancji chemicznych, dostatecznie dobre właściwości mechaniczne, a szczególnie dobre właściwości plastyczne (nawet w obniżonej temperaturze) powodują, że miedź i jej stopy są w szczególnych warunkach trudnym do zastąpienia konstrukcyjnym tworzywem metalowym.

Mimo postępującego w szybkim tempie rozwoju urządzeń i metod spawalniczych, spawanie miedzi stanowi wciąż poważny problem techniczny i nie ma obecnie łatwej technologicznie metody spawania, która pozwalałaby łączyć konstrukcje spawane w prosty sposób. Trudności występujące podczas spawania miedzi związane są z jej właściwościami fizycznymi i charakterystyką metalurgiczną.

\section{Spawalność miedzi}

Wysokie przewodnictwo cieplne miedzi utrudnia lokalne doprowadzenie metalu do temperatury topnienia i tworzenie kąpieli metalicznej, a przez to wymusza stosowanie źródeł energii o wysokim stopniu koncentracji energii lub podgrzewania przed spawaniem i podczas procesu. Podgrzewania przed spawaniem wymagają przedmioty o nawet nieznacznej grubości, tj. od ok. $3 \mathrm{~mm}$.

Kolejne właściwości fizyczne utrudniające proces technologicznego spawania to wysoki współczynnik rozszerzalności cieplnej (ok. 50\% większy niż dla stali) i znaczny skurcz odlewniczy. Są one głównymi przyczynami powstawania w złączach spawanych znacznych naprężeń własnych, a w konsekwencji dużego odkształcenia, a nawet pęknięć konstrukcji charakteryzujących się dużym stopniem utwierdzenia.

Charakter reakcji metalurgicznych zachodzących podczas spawania oraz duży wpływ obecności

Dr hab. inż. Tomasz Chmielewski, prof. PW, dr hab. inż. Dariusz Golański, prof. PW - Politechnika Warszawska, dr inż. Marek Węglowski - Rywal-RHC, Warszawa. 
niepożądanych domieszek i gazów mogą być przyczyną obniżenia odporności miedzi na powstawanie tzw. pęknięć gorących. Gazy te są z kolei główną przyczyną powstawania pęcherzy i porowatości w spoinach.

Szczególnie niebezpieczna jest obecność w miedzi bizmutu i ołowiu, które nie tworzą z miedzią roztworów stałych, ale ich kruche i niskotopliwe wydzielenia na granicach ziaren są przyczyną pęknięć gorących.

Szczególnie szkodliwą dla miedzi domieszką jest tlen, który tworzy z nią dwa typy tlenków: „czerwony” trwały podtlenek miedzi $\mathrm{Cu}_{2} \mathrm{O}$ i "czarny” nietrwały tlenek miedzi $\mathrm{CuO}$. $\mathrm{Cu}_{2} \mathrm{O}$ stanowi zwykle pozostałość z procesu wytwarzania i tworzy z miedzią eutektykę $\mathrm{Cu}_{2} \mathrm{O}+\mathrm{Cu}$ o temperaturze topnienia wyższej niż czysta miedź $\left(\mathrm{T}_{\text {top }}\right.$ miedzi $\left.-1083^{\circ} \mathrm{C}\right)$. Eutektyka w strukturze pierwotnej (odlewy i spoiny) może tworzyć siatkę wzdłuż granic ziaren lub w wyniku przeróbki plastycznej występować w korzystniejszej postaci rozproszonej. W SWC $\mathrm{Cu}_{2} \mathrm{O}$ segreguje na granicach ziaren, a w spoinie lokuje się na granicach kryształów słupkowych, powodując skłonność spoiny do kruchego pękania. Długie utrzymywanie miedzi w temperaturze bliskiej $1000^{\circ} \mathrm{C}$ skutkuje rozrostem ziarna i „nagromadzeniem” eutektyki i $\mathrm{Cu}_{2} \mathrm{O}$, a usunięcie efektów przegrzania możliwe jest tylko w procesie hutniczym. Przegrzanie można rozpoznać czerwoną barwą kruchego przełomu materiału.

Stężenie tlenu w połączeniu spawanym i SWC zależy od wielu czynników, m.in. od: gatunku miedzi, rodzaju spoiwa, metody i technologii spawania (warunków wstępnego podgrzewania). W miedzi przeznaczonej do spawania stężenie tlenu nie powinno być wyższe niż ok. 0,015\%. Przy czym należy zwrócić uwagę na to, że znaczna ilość tlenu może przeniknąć do obszaru spawania podczas wstępnego podgrzewania [3], na skutek dysocjacji CuO z warstwy wierzchniej. W takim przypadku spawanie miedzi pierwotnie nawet beztlenowej może prowadzić do istotnego wzrostu stężenia tlenu w obszarze spawania. Między innymi z tego powodu podjęto próbę opracowania technologii spawania miedzi metodą MIG bez wstępnego podgrzewania.

\section{Warunki spawania}

W ramach prowadzonych prac sprawdzono kilka odmian MIG, jednak zadowalające rezultaty uzyskano jedynie podczas stosowania odmiany SpeedPuls.

Na rysunku 1 pokazano przebieg natężenia prądu spawania i napięcia łuku w czasie w odmianie SpeedPuls.

Specyfika metody MIG-SpeedPuls polega na tym, że kształt impulsu natężenia prądu jest podobny do impulsu w odmianach Puls i TwinPuls tylko w pierwszej fazie narastania wartości natężenia prądu. W fazie amplitudowej prędkość narastania wartości natężenia prądu wyraźnie maleje. Podczas obniżania natężenia prądu w odmianie SpeedPuls jego spadek jest wolniejszy do

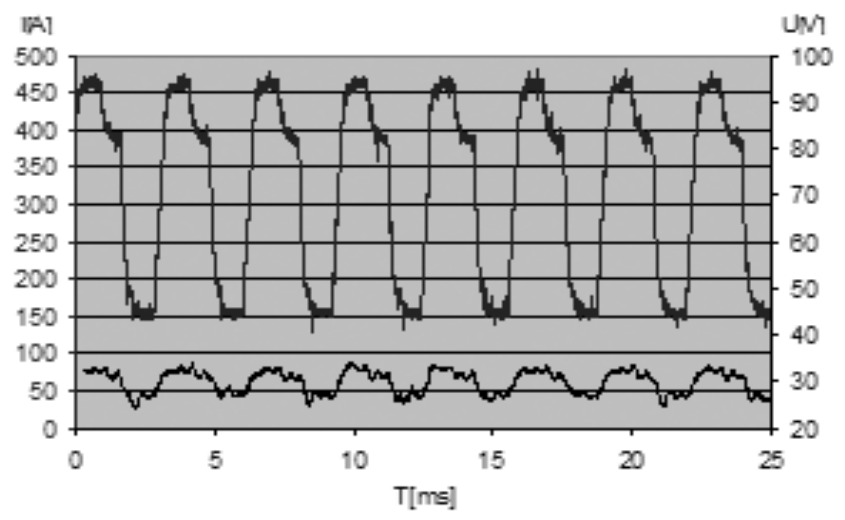

Rys. 1. Przebieg zmian natężenia prądu spawania w funkcji czasu w metodzie MIG-SpeedPuls

Fig. 1. Changes of welding current as a function of time in the MIGSpeedPuls method

ok. 2/3 wartości szczytowej (widoczny wyraźny uskok na wykresie), następnie opada podobnie jak w odmianie Puls. Dzięki takiemu kształtowaniu piku prądowego

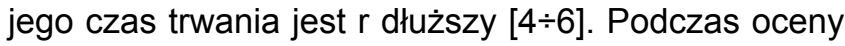
charakteru przechodzenia kropli do kąpieli metalicznej, zarejestrowanego szybkobieżną kamerą 1024 PCl firmy Photron, zaobserwowano drobnokropelkowe (strugowe) przechodzenie metalu. Może to zwiększyć energię spawania i prędkość posuwu drutu elektrodowego [7] w stosunku do metody MIG Standard.

Dodatkową zaletą metody jest to, że dzięki odpowiednio zaprogramowanej procedurze „odcinającej” krople, koniec drutu elektrodowego po procesie spawania ma stożkowy kształt, pozbawiony kropli zastygniętego metalu, utrudniającej ponowne zajarzenie łuku. Przed ponownym rozpoczęciem procesu spawania nie występuje konieczność mechanicznego obcinania końcówki drutu elektrodowego. Proces spawania SpeedPuls jest jedną z nowszych odmian metody MIG (również MAG) przeznaczoną do wysokowydajnego spawania.

Celem prowadzonych badań było uzyskanie warunków wykonania prawidłowego złącza spawanego doczołowego (spoina czołowa ukosowana na $X$ grubości $10 \mathrm{~mm}$ ) elektrolitycznej miedzi bez wstępnego podgrzewania.

Badania wykonywano w laboratorium Zakładu Inżynierii Spajania Politechniki Warszawskiej. W ramach badań wykonano złącza doczołowe $\mathrm{z}$ miedzi stosowanej na przewody elektryczne używane w elektrowniach wiatrowych. Do spawania zastosowano jako materiał dodatkowy drut spawalniczy Doex Copper Din 1733 SG-CuSn marki MOST o średnicy 1,2 mm [2], jako gazu osłonowego użyto argonu 5.0 Grupa I1 (wg PNEN ISO 14175).

Proces spawania prowadzono również w warunkach produkcyjnych, a uzyskaną wydajność porównywano z wydajnością spawania próbki wzorcowej wykonanej metodą TIG z podgrzewaniem wstępnym. Próby spawania wykonano ręcznie z zastosowaniem natężenia prądu spawania ok. 280 A. Do badań zastosowano urządzenia firmy LORCH: Saprom S (SpeedPuls). 
Do badań próbnych zaprojektowano, a następnie wykonano stanowisko badawcze. Podczas badań zastosowano spawanie ręczne, podobnie jak w rzeczywistych warunkach prefabrykacji w firmie produkcyjnej.

Na rysunku 2 widać gotowe złącza spawane po obróbce mechanicznej oraz ogólny obraz konstrukcji.

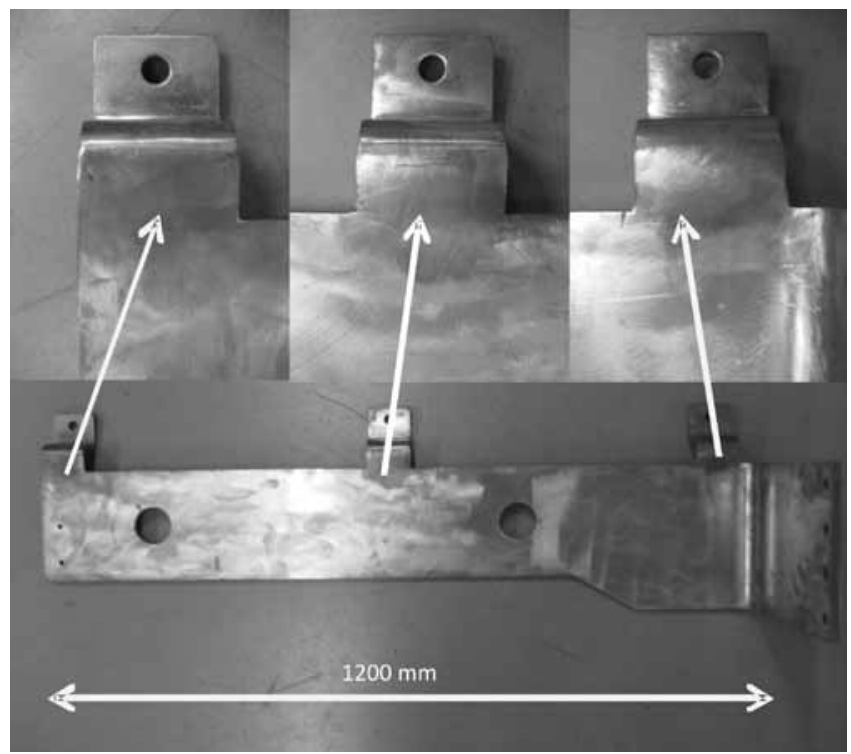

Rys. 2. Płyta miedziana o grubości $10 \mathrm{~mm}$ z zaznaczonymi spoinami Fig. 2. The copper plate with a thickness of $10 \mathrm{~mm}$ with the joints

\section{Właściwości złącza}

Na rysunku 3 przedstawiono budowę złącza spawanego ze spoiną doczołową ukosowana na $X$ niesymetrycznie. Mikrostrukturę w obszarze linii wtopienia przedstawiono na rysunku 4.

Mikrostruktura spoiny jest właściwa dla spoin stopów miedzi. Podstawowe składniki mikrostruktury to kolumnowe kryształy, charakterystyczne dla struktury pierwotnej. Ich orientacja wynika z kierunku odprowadzania ciepła ze spoiny do materiału rodzimego. Obserwowana linia wtopienia jest regularna, wtopienie nieznaczne, a mimo to brak jest przyklejeń i innych wad wtopienia mogących występować podczas spawania bez wstępnego podgrzewania.

Bardzo interesująca jest mikrostruktura obszaru wtopienia po stronie materiału rodzimego. Charakterystyczna strefa przegrzania (jaka występuje podczas spawania ze wstępnym podgrzewaniem) w tym przypadku w zasadzie nie istnieje.

Podczas wnikliwych badań struktury tego obszaru zaobserwowano jedynie nieznaczną rekrystalizację w pasmie o szerokości ok. $200 \mu \mathrm{m}$, gdzie średni wymiar ziarna wzrósł z ok. 80 do $150 \mu \mathrm{m}$. Jedynym zaobserwowanym mankamentem uzyskiwanych połączeń był wyraźny nadlew lica, który w przypadku wymaganego usunięcia obniżał uzysk spoiwa.

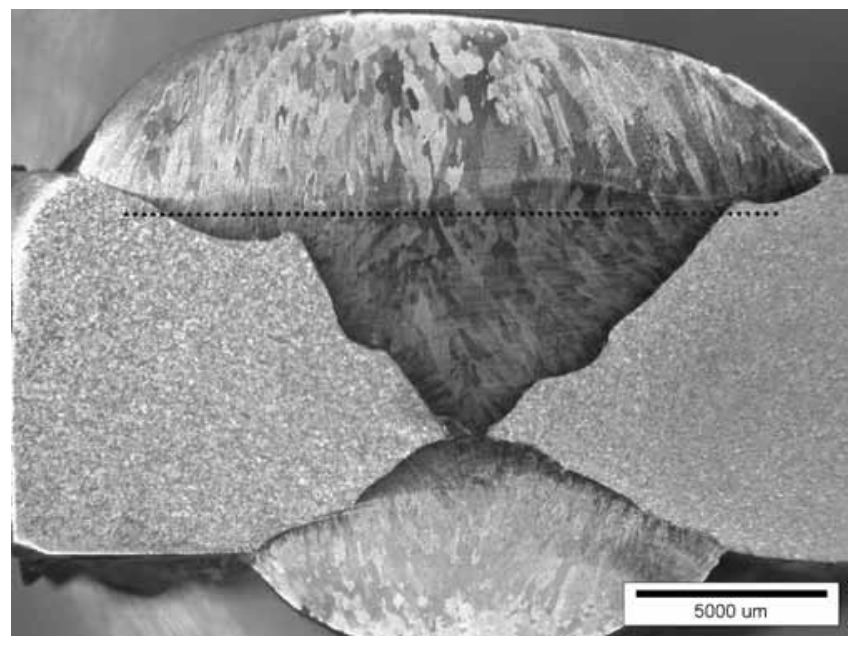

Rys. 3. Makrostruktura spoiny czołowej $X$ o grubości $10 \mathrm{~mm}$ spawanej metodą MIG-SpeedPuls bez podgrzewania wstępnego (linią przerywaną zaznaczono miejsca pomiaru twardości)

Fig. 3. Macrostructure of butt weld X $10 \mathrm{~mm}$ MIG-SpeedPuls welded without preheating (dashed line shows location of hardness testing)

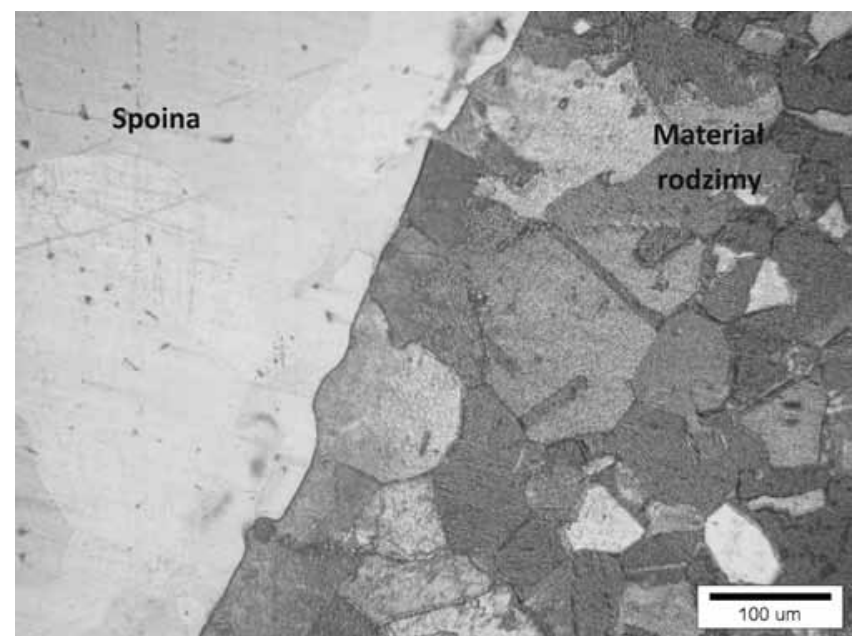

Rys. 4. Mikrostruktura obszaru linii wtopienia

Fig. 4. The microstructure of the fusion boundary area

W kolejnym etapie zbadano twardość w charakterystycznych obszarach spoiny i materiału podłoża. Pomiaru dokonano za pomocą mikroskopu z mikrotwardościomierzem - Leitz Wetzlar. Otrzymane wyniki posłużyły do wykonania wykresu rozkładu twardości w przekroju poprzecznym spoiny czołowej w linii zaznaczonej na rysunku 3.

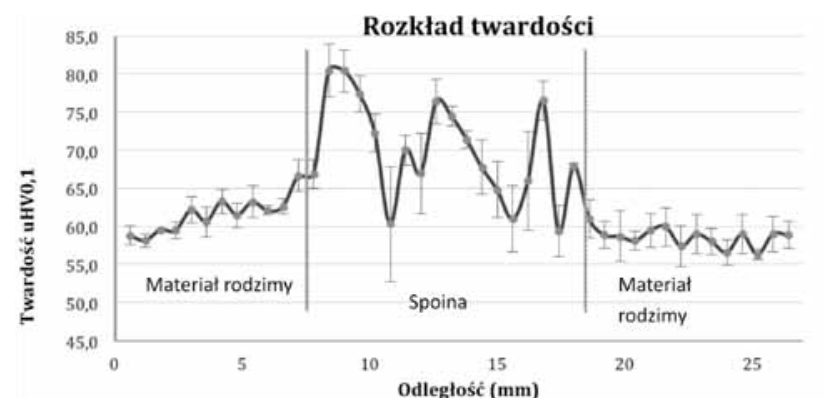

Rys. 5. Rozkład twardości w przekroju poprzecznym złącza doczołowego spoina $X$

Fig. 5. Distribution of hardness in the cross-butt weld $X$ 
$\mathrm{Na}$ rysunku 5 przedstawiono rozkład twardości w próbce pobranej ze spoiny.

$\mathrm{Na}$ wykresie zaznaczono wartości średniej arytmetycznej oraz odchylenia standardowego dla serii czterech niezależnych pomiarów.

Ze względu na małą liczbę pomiarów (cztery) ostateczny wynik został pomnożony przez tzw. współczynnik rozkładu $t$-Studenta o 3 stopniach swobody, na poziomie ufności $95 \%$.

Z przedstawionego wykresu wynika, że twardość materiału rodzimego w obszarze linii wtopienia prak- tycznie nie uległa zmianie na skutek działania cyklu cieplnego spawania.

Podczas stosowania tradycyjnego spawania z podgrzewaniem wstępnym stopów miedzi, na skutek przegrzania tej strefy i znacznej rekrystalizacji rejestruje się zwykle wyraźny nieodwracalny spadek twardości $[1,3]$.

W spoinie zaobserwowano duże różnice twardości przy jednoczesnym dużym odchyleniu standardowym. Wskazuje to na znaczne zróżnicowanie składników mikrostruktury, w tym wymiarów i orientacji kryształów.

\section{Podsumowanie}

Przeprowadzone badania dowodzą, że możliwe jest spawanie stosunkowo grubych blach miedzianych metodą MIG w odmianie SpeedPuls bez stosowania podgrzewania wstępnego. Uniknięcie wstępnego podgrzewania stopów miedzi przed spawaniem daje wymierne korzyści w postaci ograniczenia stężenia tlenu w obszarze spawania, odkształcenia i naprężeń własnych złącza oraz znacznego skrócenia czasu potrzebnego do wykonania spoiny.

Porównując wydajność spawania spoiny o grubości $10 \mathrm{~mm}$ z ukosowaniem na X metoda MIGSpeedPuls do spawania tej spoiny metodą TIG z podgrzewaniem, stwierdzono ok. 4-krotny wzrost wydajności spawania mierzony masą stopionego spoiwa w jednostce czasu. Ważną cechą uzyskanego połączenia jest brak wyraźnej strefy przegrzania występującej w większości przypadków spawania metodami łukowymi.

\section{Literatura}

[1] Chmielewski T., Golański D.: Napawanie brązu berylowego stellitem metodą MCAW. Przegląd Spawalnictwa, nr 10/2011 s. 23-27.

[2] Katalog RYWAL-RHC. Wydanie trzecie, Toruń $2011 \mathrm{r}$.

[3] LEI Yu-cheng, YU Wen-xia, LI Cai-hui, CHENG Xiao-nong.: Simulation on temperature field of TIG welding of copper without preheating. Trans. Nonferrous Met. Soc. China 16, 838842, 2006

[4] Węglowski M., Chmielewski T., Kudła K.: Porównanie wybranych właściwości nowoczesnych spawalniczych inwertorowych źródeł energii przeznaczonych do spawania metodą MAG. 51. Naukowo-Techniczna Konferencja Spawalnicza, Dębe 22-24.10.2009.
[5] Węglowski M., Chmielewski T.: Efektywność spawania w odmianach metody MAG na podstawie wybranych właściwości spawalniczych, I Konferencja Polskiej Izby Producentów Urządzeń i Usług „Nowoczesne Technologie Obróbki Metali”, Bydgoszcz, 31 marca-1 kwietnia 2011.

[6] Węglowski M., Chmielewski T.: Badania właściwości urządzeń z wewnętrzną przemianą częstotliwości przeznaczonych do spawania metodą MAG. XVII Międzynarodowa Konferencja Spawalnicza Energetyków, Opole - Turawa, 20-23 kwietnia 2010.

[7] Węglowski M., Chmielewski T., Kudła K.: Porównanie właściwości spawalniczych inwertorowych źródeł energii przeznaczonych do spawania metodą MAG. Przegląd Spawalnictwa nr 10/2009 s. 81-83.

\section{Przegląd Spawalnictwa Welding Technology Review Open Access Library}

Przegląd Spawalnictwa uruchomił możliwość wolnego dostępu do pełnych treści artykułów w ramach Open Access Library. Artykuły w języku angielskim w formacie PDF zamieszczane są na tronie internetowej redakcji: www.pspaw.ps.pl.

Autorów zainteresowanych publikacją w Open Access Library prosimy o przesyłanie artykułów w języku polskim i angielskim. W miesięczniku nastąpi publikacja w języku polskim, a tekst w języku angielskim zostanie zamieszczony na stronie internetowej. 